\title{
SCHOPENHAUER Y EL JOVEN BAROJA (El léxico del dolor y de la compasión)
}

\section{Preliminar: Schopenhauer y Baroja}

Una de las improntas presentes en Baroja es la de Arturo Schopenhauer: nosotros vamos a comprobar el tema del dolor y la conmiseración en don Pío, analizando además las manifestaciones léxicas de tal tema en varios escritos suyos juveniles. Pero para situar la cuestión creemos imprescindible referirnos antes al propio Schopenhauer.

Señalaba el filósofo de Dantzig en su obra magna El mundo como voluntad y representación que cualquier hombre puede decir: "el mundo es mi voluntad", y que el conocimiento muestra a la voluntad del hombre el dolor: el conocimiento claro, la conciencia desarrollada, aumentan el dolor.

Frente a la voluntad por tanto se alza el dolor, que define trágicamente la vida:

La vida de cada individuo — proclama Schopenhauer - ... es siempre un espectáculo trágico, pero vista en sus detalles se convierte en sainete, pues las vicisitudes y tormentos diarios... son verdaderos pasos de comedia [...] De este modo... nuestra vida encierra todos los dolores de la tragedia, arrebatándonos la dignidad de los personajes trágicos.

El mundo se le aparece a Schopenhauer en tanto el reino del azar y del error, por lo que el optimismo no es sino un sarcasmo en contra de la humanidad.

La esencia trágica de la vida lleva a la compasión —en fin—, pues percibimos entonces la unidad fundamental de todos los hombres, y esto nos lleva a la conmiseración.

El planteamiento del autor de Dantzig resulta bien conocido, pero lo hemos recordado en abreviatura porque este fondo de ideas vamos a ver que opera en los 
escritos de Baroja: la voluntad de vivir, el dolor que resulta de esa voluntad, la conciencia despierta que aumenta el dolor, la piedad hacia los demás como salida a la voluntad de vivir... Los escritos juveniles del autor vasco están impregnados de esta mentalidad conmiserativa.

\section{Una tesis doctoral: "El dolor"}

Aunque vamos a tomar datos de escritos aún más tempranos, empezamos por un texto de relieve: "El dolor", que es la tesis doctoral de Baroja y que fue editada en 1896.

Empieza a argumentar el joven Pío acerca de la cenestesia, que es como una 'sensación confusa y vaga que llega al cerebro de la reunión de las sensaciones que dan todos los órganos'; esta cenestesia además 'es el protoplasma o materia prima de la sensibilidad' (Baroja, 1973, II, pág. 356).

La cenestesia desemboca en el placer o en el dolor, según se satisfaga o contraríe tal especie de sensación de la voluntad:

Esta cenestesia o sensación confusa del estado actual del organismo, se manifiesta por necesidades o tendencias permanentes o transitorias, que cuando se satisfacen van seguidas de placer y de dolor cuando se contrarían (Ibid.).

Nos surgen pues tres vocablos: cenestesia, placer y dolor, en los que se lexicaliza la idea del cumplimiento o no de la voluntad (de vivir).

Cenestesia no aparece en el Diccionario académico de 1884 (el inmediatamente anterior al texto barojiano), ni en el siguiente de 1899; es palabra que sin embargo sí está en el tomo correspondiente del Diccionario enciclopédico hispano-americano de Montaner y Simón (1888), que define: 'la sensación vaga que tenemos de nuestro ser, independientemente del concurso de los sentidos. Se designa con este nombre la sensibilidad interna inconsciente'. No coincide por entero pues el concepto de Baroja con esta definición: Pío mantiene otra acepción, que parece más amplia, pues tiene en cuenta las sensaciones de los órganos; para él en definitiva la cenestesia 'es un conocimiento de que vivimos' (1973, II, pág. 360), y 'se manifiesta por necesidades o tendencias que son la esencia misma del hombre' (Ibid., pág. 405).

Corominas (1954) databa la palabra en 1936; no obstante la vemos ya en Baroja, y antes de él en el Diccionario de Montaner y Simón, obra de gran relieve e importancia que no deberá pasar desapercibida.

El acto de vivir lleva a la cenestesia o sensibilidad que se manifiesta en tendencias: cuando se satisfacen originan placer; cuando se contrarian, dolor. Esta concepción de tonos schopenhauerianos se verbaliza en un primer vocablo que resulta necesario, cenestesia, y en los otros dos placer y dolor. 
El Diccionario de la Academia de 1884 da para placer estas cuatro acepciones: 'contento del ánimo'; 'sensación agradable'; 'voluntad, consentimiento, beneplácito'; 'diversión, entretenimiento'. Son la segunda acepción y la primera - por este orden- las que están presentes en el uso barojiano: el logro de las tendencias de nuestra sensibilidad supone en el individuo una sensación agradable y por ello el contento del ánimo.

En cuanto al dolor aludido por Baroja, es el que definen las dos primeras acepciones del propio Diccionario de 1884 , a saber: 'sensación molesta y aflictiva de una parte del cuerpo por causa interior ó exterior'; 'sentimiento, pena y congoja que se padece en el ánimo'.

El joven Pío caracteriza tanto la cenestesia como el dolor en cuanto consisten en un conocimiento, y escribe así - según queda apuntado- respecto a una y otro: 'la cenestesia es un conocimiento consciente de la vida' (Ibid., p.360). La idea de que el conocimiento da dolor está en la tradición de la cultura y la hizo suya con gran relieve Schopenhauer; para el novelista lo mismo cabe mantener que el conocimiento lleva al dolor, que es el dolor quien nos hace conocer. Baroja se manifiesta con estas palabras:

El dolor es duradero y aporta un conocimiento;... una neuralgia nos indica el trayecto de un nervio y de sus colaterales. En el mundo moral sucede lo mismo, y así como es una gran verdad el aforismo del Eclesiastés que dice: "Quien añade ciencia añade dolor", puesto a la inversa resultaría también cierto: "quien añade dolor añade ciencia" (Ibid., pp.359-360).

Nuestro autor repara en algunos escritores románticos modernos, y comenta que lo que para los individuos normales eran accidentes irrelevantes de la vida, para ellos resultaban amarguras de una realidad llena de impurezas, motivo por el que vivieron más atormentados (Ibid.,p.363).

No deben quedar en el olvido pues ni el escrito de tesis doctoral de Baroja sobre "El dolor", ni su impregnación schopenhaueriana; el texto nos sirve además para "autorizar" con testimonios literarios algunas acepciones de varios vocablos que da el Diccionario académico de 1884, y para corregir la datación admitida hasta ahora de alguna palabra, adelantándola entre cuarenta y cincuenta años.

\section{EI léxico del dolor}

Al tiempo inmediatamente anterior e inmediatamente posterior a la tesis de doctorado de Baroja pertenecen otros escritos suyos que vamos a analizar.

El orden de preocupaciones del autor es el de la mentalidad que ejemplifica Schopenhauer: la desgracia y quienes sufren esa desgracia; el joven Pío se va a referir a esta temática con manifestaciones y léxico que empezamos a ver. Un pequeño artículo de 1893, "En el vagón de tercera", dice: 
Esas Compañías que tanto se quejan de su situación precaria, debían atender algo más a la más precaria situación de los menesterosos, y hacer que no sean los vagones en que éstos viajan helados en invierno como desfiladeros del Guadarrama y antecámaras del cementerio (Baroja, 1973,1,pág.125).

Porque hay dolor hay "menesterosos"; menesteroso es vocablo que Corominas documenta a fines del siglo XV, y que nueve años antes del escrito barojiano la Academia definía como 'falto, necesitado y que carece de una cosa ó de muchas'.

Un sentido de piedad o conmiseración está presente en las observaciones que hace nuestro autor, quien pide públicamente se atienda a un aspecto particular de la situación precaria de los "menesterosos"; precario, en esta clara acepción de "que no posee los recursos suficientes' que testimonia el texto de Baroja, no aparece sin embargo en los Diccionarios académicos de 1884 o 1899, y no estará registrado hasta el actual Diccionario de 1992.

Se comprueba por tanto un gran desfase entre los usos léxicos vigentes y su registro lexicográfico: el adjetivo precario debía tener un sentido suficientemente inequívoco y establecido en 1893 como para que lo emplease el joven Pío Baroja con toda naturalidad; la Academia sin embargo no incorpora la acepción precisa hasta casi cien años más tarde. La pérdida de respaldo filológico, de la consulta a las "autoridades" del idioma, lleva a los Diccionarios a un mayor desajuste con la realidad del habla, es decir, a resultar más inadecuados.

En su discurrir sobre el dolor en tanto sustancia de la vida humana, Baroja escribe un pequeño artículo, "La perversidad", en el que aparentemente discrepa de Schopenhauer y habla de "la misantropía del pesimista de Dantzig", pero que en definitiva enlaza con el pensamiento del filósofo aunque él ahora menciona asimismo a Poe:

El filósofo de la perversidad es Edgardo Poe, genio anómalo y gran analista que afirmaba imperturbablemente como verdad la maldad innata del hombre; ésta era para él la causa eficiente de esos inicuos hechos, que poseen a veces para el que los ejecuta el atractivo del abismo (lbid., p.127).

El dolor viene pues de la maldad o perversidad del hombre. Esta palabra perversidad la definía el Diccionario de 1884 como 'suma maldad ó corrupción de costumbres ó de la calidad ó estado debido'; perverso es, en correspondencia, 'sumamente malo'.

Otro relato muy breve de 1893 , "Noche de vela", nos sitúa en una escena de enfermedad y Baroja piensa animistamente en la "indiferencia" de las cosas ante el dolor:

Las campanadas de los relojes de la vecindad se sucedían, vibraban por largo tiempo como mostrando su indiferencia suprema por aquellos dolores (lbid., p.129). 
El dolor se encuentra presente en la vida humana, y uno de sus atributos es la indiferencia que surge ante él: indiferencia que es 'estado del ánimo, en que no se siente inclinación ni repugnancia á un objeto ó negocio determinado', según define la Academia en 1884; ya decimos que Baroja piensa ahora animistamente, pues atribuye un estado de ánimo a las campanadas de los relojes. En todo caso y como un atributo o rasgo del dolor humano está la indiferencia que despierta.

La estampa "Melancolía" es asimismo de 1893, y en ella aparece --antes por tanto de la tesis doctoral - la idea bíblica de que "quien añade ciencia añade dolor" (Ibid., p.132); tres años más tarde publica Baroja "El enfermo", y habla de la "desgracia" de unos personajes:

Así él pagaba la culpa de su padre, aristócrata vicioso que había labrado antes de su muerte la desgracia de su mujer y la de su hijo, al engendrarle a éste débil y enclenque, al transmitirle su sangre viciada, escasa en glóbulos rojos y rica en podredumbres orgánicas (Ibid., p.199).

Ahora desgracia parece empleado en la acepción 'motivo de aflicción originado de caso ó acontecimiento contrario á lo que convenía ó se deseaba' que recoge el Diccionario de 1884, aunque la expresión la desgracia de su hijo aglutina a la vez la acepción desgracia 'menoscabo en la salud' del mismo registro académico.

El tema schopenhaucriano del dolor lleva a que en los escritos del joven Pío Baroja se lexicalicen ideas concomitantes en palabras como menesterosos, precario, perversidad, indiferencia o desgracia, y a que estas palabras bien sirvan como "autoridad" literaria que confirma las acepciones del Diccionario académico —en este caso el de 1884-, bien constituyan también "autoridad" de la que la lexicografía no debiera haber prescindido para no quedarse atrás.

\section{La "cosa" y la palabra "golfo"}

Un artículo barojiano de 1897 aborda el asunto de los "Golfos", y a lo mismo vuelve luego el autor en un capitulillo de Vidas sombrías ("Patología del golfo"), y en el escrito "Crónica: Hampa" de 1903 (cfr. Abad, 1995).

Estamos en el mismo mundo de la desgracia y los menesterosos, del dolor y la compasión schopenhaueriana ante ese dolor; surge por entonces esta manifestación social de los "golfos" y es Baroja quien nos testimonia que se trata de "una palabra nueva" para "una cosa nueva".

¡Golfos! —escribe- He aquí una palabra nueva, pintoresca, de esas que se inventan y corren en seguida de boca en boca, de esas que señalan algo desconocido hasta cl momento, una cosa nueva, una idea más gráfica, más exacta, más descarnada. El golfo es un tipo nuevo que surge de nuestro gastado fondo social... Es un tipo trágico más bien que cómico... A cambio de sus trabajos y 
de sus esfuerzos, no quiere... satisfacer sólo sus necesidades, sino también sus pasiones y sus vicios (Baroja, 1973, I, pág. 265-266).

Tenemos un testimonio exacto del nacimiento de una palabra en correspondencia con el nacimiento de un tipo social nuevo: el joven Pío se da cuenta de ambas cosas y las manifiesta claramente.

Si reparamos en la clase pobre - se extiende nuestro autor- vemos al golfo "siempre en guardia, siempre al acecho" (Ibid., pág. 266); entre los golfos de la clase media hay dos tipos opuestos: el golfo vulgar que odia, y el que filosofa. El golfo vulgar de clase media es un envidioso que se consume al ver que no prospera, mientras el golfo de la misma clase media que filosofa, comprende que sus miserias vienen de su pereza (Ibid., págs. 267-268).

Poseemos un testimonio sobre la palabra golfo casi inmediatamente posterior al de Baroja, y no menos precioso: en un artículo de 1900 acerca de "Etimologías españolas" trató Menéndez Pidal de golfín, golfo, y decía:

Los golfines eran gente de mal vivir que, formando bandas de salteadores, infestaban las jaras y los montes de Castilla en los comienzos del siglo XIV, y se aplicó también el mismo nombre al bribón ó truhán en general... En cuanto á golfo, golfa, que hace unos 10 ó 12 años se usa en Madrid para denotar "pilluelo, vagabundo", parece una resurrección de la voz golfín desprovista de su sufijo diminutivo (Menéndez Pidal, 1900, pág.353).

Hacia 1890 por tanto resultaba una novedad de la vida madrileña la palabra golfo, y el joven Baroja muestra ya la veracidad que preside toda su obra y la agudeza que le distinguió en captar los fenómenos sociales; el asimismo joven Ramón Menéndez Pidal discurre técnicamente sobre el vocablo.

La palabra golfo aparece registrada por vez primera en el Diccionario académico en 1914, en el que se la define con el significado de 'pilluelo, vagabundo, embaidor'; acaso fue el propio Menéndez Pidal, académico desde 1902, quien llevó la iniciativa de incorporar el neologismo y quien redactó la acepción de manera tan análoga a como lo había hecho en su artículo de 1900.

En 1954 Corominas acepta la propuesta etimológica de don Ramón, y añade por su parte que si bien "no puedo -dice-documentar golfín 'bribón' después del S.XV, creo sin embargo que el vocablo se conservaría localmente en el habla popular como tantos arcaísmos, y que de ahí deriva realmente el golfo madrileño".

El mundo de los menesterosos humanos y de su precaria situación ha llevado al joven Baroja hacia este mundo o submundo de los "golfos", hacia algunos de los cuales expresará su conmiseración; al hacerlo nos transmite asimismo el testimonio del surgimiento de la palabra, lo que — desde una perspectiva técnica-filológicahará por igual Menéndez Pidal. 


\section{Baroja ante la innovación léxica}

La última de las estampas de Vidas sombrias (1900) es la "Patología del golfo", y consiste en una reelaboración del artícuio que ya conocemos de 1897 "Golfos". La presente estampa se inicia con un testimonio explícito otra vez acerca no ya de la realidad de la golfería, sino del vocablo golfo; estamos ante un pasaje que se publica exactamente a la vez que el análisis etimológico de Ramón Menéndez Pidal, y que dice ahora en párrafo largo pero necesario:

Cuando en un idioma aparece una palabra nueva, es porque en su fondo ha germinado una idea, un producto, un tipo, algo también nuevo; y si la palabra surge y se generaliza y corre de boca en boca, entonces indudablemente la palabra llena un vacío, señala una cosa hasta entonces sin nombre. Esto ha pasado con la palabra golfo. Se inventó donde se inventan esas cosas: en un presidio, en algún lupanar; comenzó a usarse entre la gente del bronce, pasó al periódico, Iuego al teatro, y se hizo del dominio común (Baroja, 1991, pág. 188).

Las palabras de nuestro autor muestran entera agudeza: surge algo nuevo y hace falta una palabra asimismo nueva para eso que no tiene nombre; Ia palabra la inventa alguien en un ámbito reducido, comienza a usarse luego (esto es, a extenderse), y luego se generaliza y pasa al dominio común.

Pío Baroja describe exactamente cómo se cumple una innovación léxica: necesidad de llenar el vacío expresivo ante algo nuevo, innovación o invención en el vocabulario, y generalización de la nueva palabra. En este caso se inventa la voz golfo y empieza a usarse - señala el novelista - entre la "gente del bronce", es decir, la gente 'alegre y resuelta', según define el Diccionario académico de 1899 inmediatamente anterior al texto barojiano; luego desde esta gente del bronce la palabra pasa a los centros de generalización idiomática entonces, la prensa y el teatro, y por fin se hace del dominio común. En términos de la ciencia lingüística cabría decir que la innovación léxica surge de una invención individual, que luego se va extendiendo por medios más y más generales, y que al fin se estabiliza dando lugar a un cambio idiomático que pertenece ya no al hablar individual o de grupo sino a la "lengua" toda en sentido saussureano.

Define el joven Baroja al golfo -luego de habernos advertido acerca de la novedad de la palabra y de la realidad social a la que se refiere-, y dice de manera concreta sobre este tipo de la vida social: 'es un tipo separado por una causa cualquiera de su medio ambiente, y que reúne en sí mismo todas las aspiraciones de su clase' (Ibid., pág. 189). Insiste Baroja en que en efecto el golfo está desligado de su clase, y que posee una filosofía propia que es en general la negación de toda moral (Ibid., p.190); estamos ante el egotismo (vocablo barojiano ausente del léxico académico de 1899) o filosofía del yo: “Al perder [el golfo] la moral de su medio ambiente, al no tener utilidad para él los preceptos morales de su clase, desaparece de su espíritu toda relación de deber para con los demás (Ibid., pp. 192-193). 
En este escrito de Vidas sombrías repite Baroja la observación de que "entre los miserables el golfo no es un holgazán" (Ibid., p.193); miserable lo emplea el novelista en el sentido de la tercera acepción académica en 1899, en el de "desdichado, infeliz'. Asimismo vuelve el novelista a su diferenciación entre "el golfo que odia" y el más raro golfo "que filosofa", aunque tales dos tipologías las adscribe ahora no sólo en la burguesía —como en 1897-, sino asimismo entre la aristocracia.

\section{El "hampa"}

A la golfería o conjunto de golfos se refiere en fin el joven Pío en su aludido artículo de 1903 "Crónica: Hampa", lleno de un aliento de misericordia (en el mejor sentido del concepto) hacia la gente abandonada; el tono de compasión schopenhaueriana es aquí muy patente:

Madrid está rodeado de suburbios en donde vive ... un mundo de mendigos, de miserables, de gente abandonada. ¿Quién se ocupa de ellos? Nadie, absolutamente nadie. Yo ... he visto golfos andrajosos salir gateando de las cuevas del cerrillo de San Blas y les he contemplado cómo devoraban gatos muertos... $Y$ no he visto a nadie que se ocupara en serio de tanta tristeza, de tanta laceria (Baroja, 1973,II,pp.331-332).

Como decimos el tono de piedad hacia los sufrimientos destaca ahora mucho, aunque no se encuentra ausente en general de estos escritos juveniles de don Pío y aun de todos sus escritos; está hablando del hampa, palabra que en el Diccionario académico de 1899 no tiene acepción que se aproxime al sentido en que la usa Baroja, y que sólo en el Diccionario de 1925 aparecerá en tanto 'vida de holgazanería picaresca y maleante', que nada más en parte se acerca al empleo que estamos viendo.

Luego en 1970 hampa es asimismo para la Academia la 'gente que lleva esta vida' maleante, pero las distintas acepciones que da el Diccionario académico hasta nuestros días no encajan con la significación barojiana de 'gente abandonada, miserables', sin más. El tono de las definiciones oficiales está siempre un tanto sesgado negativamente, sin que aparezca la pura denotación de 'gente miserable'.

Baroja expresa toda su sensibilidad en contra de la sordidez social en las páginas presentes, que asimismo proclaman:

La diferencia es demasiado patente, el rico no quiere comprender, se encastilla en su indiferencia; el pobre que nada puede hacer por ahora más que rebelarse, se encastilla en su odio... No, esa indiferencia ni es humana, ni es justa, ni es siquiera prudente (Ibid., p. 333).

La indiferencia animista de las cosas materiales ante el dolor humano ya había sido registrada por Baroja; ahora se trata de la indiferencia del hombre hacia el hombre, que ni es justa ni resulta prudente, según advierte Pío. 


\section{Algunas conclusiones}

1. El Pío Baroja más joven muestra una clara impronta del pensamiento de Schopenhauer, y así mantiene la tesis de que el conocimiento da dolor y de que a la vez el dolor añade conocimiento.

2. Encontramos también en el joven novelista la compasión o conmiseración schopenhaueriana hacia los menesterosos y sufrientes.

3. Al desplegar este orden de ideas Baroja hace empleo de un léxico en el que hay que advertir:

a) Aunque el vocablo cenestesia está datado en 1936, lo usan Pío y aun antes de él el "Diccionario" de Montaner y Simón casi medio siglo antes.

b) La palabra precario en el significado de "que no posee los recursos suficientes' la "autoriza literariamente Pío en 1893, pero no llegará al Diccionario académico hasta casi cien años más tarde.

c) Nuestro autor documenta explícitamente el nacimiento de la palabra golfo, asimismo documentada como vivencia idiomática personal por Menéndez Pidal.

d) Don Ramón deriva razonablemente golfo de golfin, y quizá impulsa en persona la incorporación de la palabra al Diccionario de la Academia (1914), y la define.

e) Con gran nitidez discursiva, Baroja explica muy bien a propósito de golfo cómo se producen la innovación y el cambio léxicos.

f) La voz hampa no posee todavía en el Diccionario académico las acepciones 'vida de los menesterosos' o 'gente que lleva esta vida' que resulten meramente denotativas, sin connotación peyorativa alguna.

\section{REFERENCIAS BIBLIOGRÁFICAS}

ABAD, Francisco. 1995. "Sobre la bohemia", en Literatura y arte: Lorca, Buñuel, Picasso, Madrid, UNED.

BAROJA, Pío.1973. Hojas sueltas, Madrid, Caro Raggio.

-1991. Vidas sombrías, Madrid, Caro Raggio.

COROMINAS, J. 1954. Diccionario crítico etimológico de la lengua castellana, Madrid, Gredos.

MENÉNDEZ Pidal, Ramón. 1900. “Etimologías españolas”, Romania, XXIX, págs. 334-379.

REAL ACADEMIA ESPAÑOLA, 1884, 1899, 1914. Diccionario de la lengua castellana, Madrid.

-1925, 1970. Diccionario de la lengua española, Madrid. 